\title{
Aerosol information content analysis of multi-angle high spectral resolution measurements and its benefit for high accuracy greenhouse gas retrievals
}

\author{
C. Frankenberg ${ }^{1}$, O. Hasekamp ${ }^{2}$, C. O'Dell ${ }^{3}$, S. Sanghavi ${ }^{1}$, A. Butz ${ }^{4}$, and J. Worden ${ }^{1}$ \\ ${ }^{1}$ Jet Propulsion Laboratory, California Institute of Technology, Pasadena, USA \\ ${ }^{2}$ SRON Netherlands Institute for Space Research, Utrecht, The Netherlands \\ ${ }^{3}$ Colorado State University, Fort Collins, CO, USA \\ ${ }^{4}$ Karlsruhe Institute of Technology, IMK-ASF, Karlsruhe, Germany \\ Correspondence to: C. Frankenberg (christian.frankenberg@jpl.nasa.gov)
}

Received: 1 April 2012 - Published in Atmos. Meas. Tech. Discuss.: 16 April 2012

Revised: 29 June 2012 - Accepted: 3 July 2012 - Published: 27 July 2012

\begin{abstract}
New generations of space-borne spectrometers for the retrieval of atmospheric abundances of greenhouse gases require unprecedented accuracies as atmospheric variability of long-lived gases is very low. These instruments, such as GOSAT and OCO-2, typically use a high spectral resolution oxygen channel $\left(\mathrm{O}_{2}\right.$ A-band) in addition to $\mathrm{CO}_{2}$ and $\mathrm{CH}_{4}$ channels to discriminate changes in the photon path-length distribution from actual trace gas amount changes. Inaccurate knowledge of the photon path-length distribution, determined by scatterers in the atmosphere, is the prime source of systematic biases in the retrieval. In this paper, we investigate the combined aerosol and greenhouse gas retrieval using multiple satellite viewing angles simultaneously. We find that this method, hitherto only applied in multi-angle imagery such as from POLDER or MISR, greatly enhances the ability to retrieve aerosol properties by 2-3 degrees of freedom. We find that the improved capability to retrieve aerosol parameters significantly reduces interference errors introduced into retrieved $\mathrm{CO}_{2}$ and $\mathrm{CH}_{4}$ total column averages. Instead of focussing solely on improvements in spectral and spatial resolution, signal-to-noise ratios or sampling frequency, multiple angles reduce uncertainty in space based greenhouse gas retrievals more effectively and provide a new potential for dedicated aerosols retrievals.
\end{abstract}

\section{Introduction}

The Greenhouse Gases Observing Satellite (GOSAT) (Hamazaki et al., 2005; Kuze et al., 2009) and the Orbiting Carbon Observatory (OCO) (Crisp et al., 2004) are new missions dedicated to the retrieval of greenhouse gas column averaged mixing ratios (denoted $\mathrm{X}_{\mathrm{CO}_{2}}$ or $\mathrm{X}_{\mathrm{CH}_{4}}$ ). Owing to the long atmospheric lifetime of these gases, abundances in the atmosphere across the globe vary by only a few percent, warranting sub-percent accuracy and precision to improve our current understanding of land-atmosphere fluxes on regional scales (Miller et al., 2007). Both spectrometers feature three high resolution spectral bands, centred around $0.76 \mu \mathrm{m}$ $\left(\mathrm{O}_{2}\right.$ A-band), $1.61 \mu \mathrm{m}$ (weak $\mathrm{CO}_{2}$ band) and $2.06 \mu \mathrm{m}$ (strong $\mathrm{CO}_{2}$ band). As opposed to ground-based direct sun spectra such as from the TCCON network (Wunch et al., 2011), the exact light-path distribution of recorded photons is not known from the nadir space-borne viewpoint, causing ambiguities between light-path and trace-gas amount changes. To mitigate this general retrieval problem, full-physics algorithms (e.g., Bösch et al., 2006; Boesche et al., 2009; Butz et al., 2009; O'Dell et al., 2012) simultaneously fit multiple channels using radiative transfer calculations, concurrently retrieving $\mathrm{X}_{\mathrm{CO}_{2}}, \mathrm{X}_{\mathrm{CH}_{4}}$, surface albedos as well as a set of aerosol properties, the prime contributor to photon pathlength changes. Also for SCIAMACHY (Bovensmann et al., 1999), multi-band retrievals have been developed fitting the $\mathrm{O}_{2}$ A-band and a weak $\mathrm{CO}_{2}$ band at moderate spectral resolution (Reuter et al., 2010). 
Most retrieval errors are related to scattering, causing errors in the forward model with simplified aerosol assumptions (Butz et al., 2009; O'Dell et al., 2012). Aerosols in the atmosphere vary wildly in chemical composition, particle size and particle vertical distribution (Herman et al., 1997; Kahn et al., 2001; Maso et al., 2005). A full-physics retrieval, however, only represents a subset of potential aerosol properties and even those can be under-constrained. Dedicated aerosol imagers such as the POLarization and Directionality of Earth Reflectances (POLDER, Leroy et al., 1997) and the Multi-angle Imaging SpectroRadiometer (MISR, Diner et al., 1998) use intensities (and polarization) measured at various viewing angles along the flight direction to improve their aerosol retrieval capability. They sample the aerosol phase function at various scattering angles, providing insight into their microphysical properties such as particle size distribution or refractive index (e.g. Hasekamp and Landgraf, 2007; Lebsock et al., 2007) or cloud structure (Ferlay et al., 2010). Even for dedicated aerosol sounders, however, a consolidated view on the global distribution of aerosol properties is not yet achieved (Mishchenko et al., 2007), underlining the complexity in general, not withstanding its impact on trace gas retrievals. Any improvement in aerosol retrieval capabilities will, thus, improve both our understanding of the impact of aerosols in the climate system and reduce systematic biases in trace gas retrievals. Both problems are intricately coupled through the impact aerosols on the diffuse radiation field.

In this study, we apply the multi-angle principle to high spectral-resolution radiances covering absorption features. Polarization can provide further information (Leroy et al., 1997; Lebsock et al., 2007) especially on particle size, but here we focus solely on the benefits of information from resolved absorption spectra. OCO-2, planned to launch in late 2014, will deliver multi-angle soundings in target mode, in which it will stare at validation sites while the satellite passes over (see Fig. 1).

The structure of the paper is as follows: Sect. 2 describes the retrieval setup, including the forward model and information content analysis framework. Section 3 analyses the information content for aerosols using 3-band and 2-band retrieval setups for the nadir-only and multi-angle viewing cases. Section 4 describes the impact of enhanced aerosol information on the posterior error estimates for $\mathrm{CO}_{2}$ and $\mathrm{CH}_{4}$ total column amounts. Section 5 provides a short outlook into necessary future steps as well as the overall potential and Sect. 6 summarises the general findings of this manuscript.

\section{Retrieval setup}

Retrieval methods often rely on the implementation of a forward model $F$, linking the measurement vector $\boldsymbol{y}$ with a set of state vector elements $\boldsymbol{x}$ to be retrieved:

$\boldsymbol{y}=F(\boldsymbol{x})+\epsilon$,

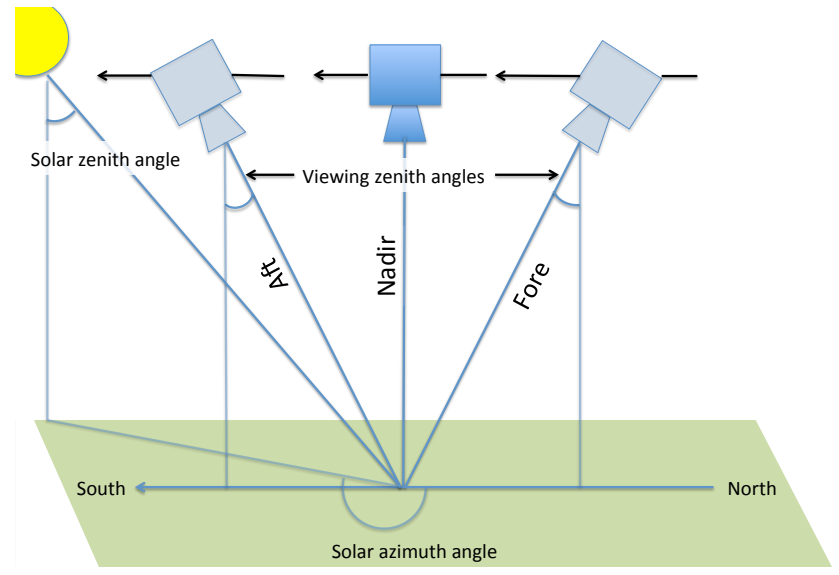

Fig. 1. Schematics of a generic multi-angle viewing mode using the satellite motion in low earth orbit instead of multiple spectrometers to record the same scene at various angles (similar to the OCO-2 target mode). Satellite viewing azimuth angles in this case are $0^{\circ}$ and $180^{\circ}$ for aft and fore viewing modes, respectively (angle with respect to the north-facing vector).

where $\epsilon$ represents measurement noise. In the optimal estimation approach (Rodgers, 2000), a priori knowledge on the state vector can be quantified by its a priori $\boldsymbol{x}_{\mathrm{a}}$ and a priori covariance matrix $\mathbf{S}_{\mathrm{a}}$, resulting in a cost function consisting of weighted deviations between model and measurement vectors as well as retrieved state vector and a priori state vector:

$\chi^{2}=(\boldsymbol{y}-F(\boldsymbol{x}))^{T} \mathbf{S}_{\epsilon}^{-1}(\boldsymbol{y}-F(\boldsymbol{x}))+\left(\boldsymbol{x}_{\mathrm{a}}-\boldsymbol{x}\right)^{T} \mathbf{S}_{\mathrm{a}}^{-1}\left(\boldsymbol{x}_{\mathrm{a}}-\boldsymbol{x}\right)$.

The solution to a nonlinear problem such as ours requires iterations to solve for $\hat{\boldsymbol{x}}$, which minimizes the cost function $\chi^{2}$ :

$$
\begin{aligned}
\hat{\boldsymbol{x}}_{i+1}= & \boldsymbol{x}_{\mathrm{a}}+\left(\mathbf{K}_{i}^{T} \mathbf{S}_{\epsilon}^{-1} \mathbf{K}_{i}+\mathbf{S}_{\mathrm{a}}^{-1}\right)^{-1} \mathbf{K}_{i}^{T} \mathbf{S}_{\epsilon}^{-1} \\
& \cdot\left(\boldsymbol{y}-F\left(\boldsymbol{x}_{i}\right)+\mathbf{K}_{i}\left(\boldsymbol{x}_{i}-\boldsymbol{x}_{\mathrm{a}}\right)\right)
\end{aligned}
$$

where $\mathbf{S}_{\epsilon}$ represents the measurement vector covariance matrix, diagonal in our case where no cross-talk between individual detector pixels is assumed. The derivative of the forward model $F$ with respect to $\boldsymbol{x}$, denoted as Jacobian $\mathbf{K}$ matrix, is also needed:

$\frac{\partial F(\boldsymbol{x})}{\partial \boldsymbol{x}}=\mathbf{K}$.

The greenhouse gas retrievals described in Bösch et al. (2006) and O'Dell et al. (2012) use this approach to derive column amounts of greenhouse gases alongside aerosol properties. In this particular case, $\boldsymbol{x}$ comprises elements related to aerosols (such as aerosol profiles for various types or microphysical properties as in Butz et al., 2009), trace gas profiles, surface albedos and their wavelength dependence for three separate spectral ranges as well as instrumental effects 
Table 1. State vector elements used in the simulations separated for aerosol parameters for a mono-modal size distribution (spherical) as well as surface and trace gas parameters. Aerosol size distribution is defined as 2-parameter gamma distribution according to Hansen and Travis (1974). BRDF scaling factors per band are roughly equivalent to the Lambertian albedos observed over Lamont. $\tau$ denotes aerosol optical density AOD.

\begin{tabular}{|c|c|c|c|c|}
\hline & state vector element & a priori & a priori $1 \sigma$ & unit \\
\hline \multirow{8}{*}{ 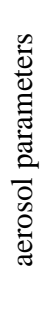 } & effective radius & 1.0 & 1.0 & $\mu \mathrm{m}$ \\
\hline & effective width & 0.4 & 0.4 & - \\
\hline & real refractive index & 1.4 & 0.15 & - \\
\hline & imaginary refractive index & 0.003 & 0.01 & - \\
\hline & aerosol column & $9.75 \times 10^{10}$ & $5 \times$ prior & $\mathrm{m}^{-2}$ \\
\hline & & $\tau \approx 0.100$ at 0.77 & $\mu \mathrm{m} ; 0.090$ at $1.61 \mu \mathrm{m} ; 0$ & 776 at $2.06 \mu \mathrm{m}$ \\
\hline & aerosol profile centre height & 5.0 & 3.0 & $\mathrm{~km}$ \\
\hline & aerosol profile centre width & 2.0 & 2.0 & $\mathrm{~km}$ \\
\hline \multirow{13}{*}{ 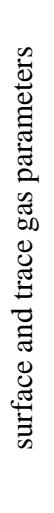 } & Roujean kernel band 1 & 0.14 & 0.5 & - \\
\hline & Ross thick kernel band 1 & 0.45 & 0.5 & - \\
\hline & BRDF scaling band 1 & 0.276 & 0.5 & - \\
\hline & Roujean kernel band 2 & 0.14 & 0.5 & - \\
\hline & Ross thick kernel band 2 & 0.45 & 0.5 & - \\
\hline & BRDF scaling band 2 & 0.2168 & 0.5 & - \\
\hline & Roujean kernel band 3 & 0.14 & 0.5 & - \\
\hline & Ross thick kernel band 3 & 0.45 & 0.5 & - \\
\hline & BRDF scaling band 3 & 0.10 & 0.5 & - \\
\hline & $\mathrm{O}_{2}$ total column & $4.5 \times 10^{24}$ & $0.2 \%$ & molec $\mathrm{cm}^{-2}$ \\
\hline & $24 \mathrm{CO}_{2}$ sub-columns & $\sum=7.1 \times 10^{21}$ & $1 \%$ of total, diagonal & molec $\mathrm{cm}^{-2}$ \\
\hline & $\mathrm{CH}_{4}$ total column & $3.75 \times 10^{19}$ & $5 \%$ & molec $\mathrm{cm}^{-2}$ \\
\hline & $\mathrm{H}_{2} \mathrm{O}$ total column & $9 \times 10^{21}$ & $100 \%$ & molec $\mathrm{cm}^{-2}$ \\
\hline
\end{tabular}

such as spectral shifts. The full measurement vector $\boldsymbol{y}$ for the Nadir viewing case is a concatenation of radiances observed by $n$ spectra recorded by individual spectrometers

$\boldsymbol{y}_{\text {nadir }}=\left[\boldsymbol{y}_{\text {band }_{1}}^{T}, \ldots, \boldsymbol{y}_{\text {band }_{n}}^{T}\right]^{T}$,

where in our case (2-3 bands) band through band $_{3}$ represent the $\mathrm{O}_{2}$ A-band, weak and strong $\mathrm{CO}_{2}$ band, respectively.

To concurrently exploit the information from observations at multiple angles, we must further extend the measurement vector, concatenating multiple viewing geometries for nadir, aft and fore viewing geometries (in our case we choose 3 angles, but the general framework can be extended to an arbitrary number):

$\boldsymbol{y}=\left[\boldsymbol{y}_{\text {fore }}^{T}, \boldsymbol{y}_{\text {nadir }}^{T}, \boldsymbol{y}_{\mathrm{aft}}^{T}\right]^{T}$.

For the comparison of the multi-angle mode with nadir-only retrievals, we concatenate $\boldsymbol{y}_{\text {nadir }}$ three times for the nadironly retrievals, ensuring that the measurement vector is of the same size with geometry being the only difference.

Adding bands and/or angles in the measurement vector does not affect the general structure of the state vector $\boldsymbol{x}$ (with the exception of adding instrumental parameters such as spectral shift per band and viewing angle). For technical reasons, forward model and Jacobians are first individually determined per band and then properly concatenated to reflect the full measurement vector.

Here, we follow the approach of Butz et al. (2009), representing aerosol parameters by their microphysical properties. Table 1 lists the set of 7 aerosol state vector elements considered in this study. The main difference to the current nadironly retrievals (Butz et al., 2009; O'Dell et al., 2012), is that we specifically include a bi-directional surface reflectance function for each spectral band described by:

$$
\begin{aligned}
\operatorname{BRDF}\left(\theta_{\mathrm{s}}, \theta_{\mathrm{v}}, \phi, \lambda\right) & =f_{\text {iso }}(\lambda)+f_{\mathrm{vol}}(\lambda) K_{\mathrm{vol}}\left(\theta_{\mathrm{s}}, \theta_{\mathrm{v}}, \phi\right) \\
& +f_{\text {geo }}(\lambda) K_{\text {geo }}\left(\theta_{\mathrm{s}}, \theta_{\mathrm{v}}, \phi\right)
\end{aligned}
$$

where $f_{\text {iso }}$ describes isotropic scattering and the kernels $K_{\text {vol }}$ and $K_{\text {geo }}$ describe volume and geometric scattering, respectively (also adapted by the official MODIS BRDF product, Schaaf et al., 2002). $\theta_{\mathrm{s}}, \theta_{\mathrm{v}}$ and $\phi$ denote the solar zenith angle, viewing zenith angle and relative azimuth angle, respectively. Here, we use the kernel model known as the RossRoujean model (see e.g., Roujean et al., 1992 and Wanner et al., 1995). The coefficients $f_{\text {iso }}, f_{\text {vol }}$ and $f_{\text {geo }}$ for each band are included in the state vector as unknown parameters because the angular dependence of the surface albedo becomes more important in the multi-angle view. A priori values are chosen to represent a mix of surface and vegetation (Litvinov et al., 2011). The application of a pure Lambertian albedo, as used in nadir retrievals, would impose an 
implicit hard constraint on the surface type and might thus lead to an overestimation of the aerosol information content contained in the multi-angle mode.

\subsection{Forward model}

The forward model is based on radiative transfer computations linking optical properties determined by the state vector $\boldsymbol{x}$ as well as ancillary information on surface pressure and temperature profiles to the measurement $\boldsymbol{y}$. The core of the forward model is the vector radiative transfer model (RTM) developed by Hasekamp and Landgraf (2002, 2005) and Hasekamp and Butz (2008). The RTM calculates the Stokes vector of solar radiation backscattered to space by the Earth's surface and atmosphere considering molecular and particulate absorption as well as multiple scattering by molecules and particles in a multilayer, inhomogeneous, plane parallel atmosphere that consists of 24 layers. Molecular absorption and scattering properties are readily derived from spectroscopic databases and Rayleigh scattering theory. Particle optical properties, scattering and absorption cross sections and scattering phase matrices, are computed by Mie theory assuming a spherical shape of the particles. In this study aerosols are described assuming a monomodal log-normal size distribution, yielding 4 microphysical aerosol parameters: effective radius, effective variance, real and imaginary part of the refractive index, as well as 3 parameters related to amount and height distribution (aerosol number column density, effective height, effective width of height distribution, see Table 1 and Butz et al., 2009).

\subsection{Simulation scenarios}

For highly nonlinear retrieval problems, the impact of multiangle viewing geometries can vary widely between scenes, depending on solar zenith angle, surface albedos as well as aerosol amount and properties. Here, we restrict our analysis to a conceptual study using two scenarios over Lamont, Oklahoma in summer and winter, respectively. Solar geometries are taken from GOSAT (Kuze et al., 2009) soundings on 3 July 2009 and 27 November 2009, respectively. The aerosol phase function used in the simulations as well as the scattering angles corresponding to the two scenarios are depicted in Fig. 4.

For the surface albedo, we choose typical summer albedos over Lamont for both summer and winter cases (as to not confuse change in information content due to surface albedo changes with solar geometry changes). For simplicity, we only use 3 different viewing geometries; namely strict nadir as well as $30^{\circ}$ fore and aft viewing zenith angle at 0 and $180^{\circ}$ azimuth (i.e., strictly North-South). Table 2 summarises the two scenarios and corresponding scattering angles.

Figures 2-3 depict Jacobians with respect to aerosol state vector elements as well as $\mathrm{CO}_{2}$ for the summer and winter scenario, respectively. Each row represents the Jacobian of
Table 2. Angles used in the simulation scenarios. Azimuth angles for the fore and aft satellite viewing are $180^{\circ}$ and $0^{\circ}$, respectively (i.e., straight south and north-looking). Satellites viewing angles for those off-nadir geometries are always $30^{\circ}$.

\begin{tabular}{lccl}
\hline & $\begin{array}{c}\text { solar zenith } \\
\left({ }^{\circ}\right)\end{array}$ & $\begin{array}{c}\text { solar azimuth } \\
\left({ }^{\circ}\right)\end{array}$ & $\begin{array}{l}\text { scattering angles } \\
\text { Nadir, fore, aft }\left(^{\circ}\right)\end{array}$ \\
\hline winter & 64.32 & 200.4 & $115.68,142.91,87.31$ \\
summer & 19.46 & 238.8 & $160.54,154.53,136.90$ \\
\hline
\end{tabular}

the full measurement vector, subdivided by spectral bands (different panels) and viewing angles (colour-coded per panel). Intuitively, the benefit of multiple viewing angles increases with the dissimilarity of Jacobians at different angles. The largest similarity between different viewing angles is found for the derivative with respect to changes in the $\mathrm{CO}_{2}$ concentration (lowest panel). The derivative with respect to the real refractive index, however, is very dissimilar, showing largely different radiance changes in the continuum as well as an opposing change in the shape of the absorption lines, in particular in the $\mathrm{O}_{2}$ A-band. Since the real refractive index has a strong impact on the aerosol phase function and, hence, on the angular distribution of scattering, this behaviour is expected, but cannot be exploited in nadir-only viewing geometries.

The depiction of the reflectances as well as Jacobians is for purely illustrative purposes and in order to get a more physical insight why the formally derived information content, as described in the following section, changes when adding multiple geometries. However, potential interference errors can also be easily visualised: e.g., the weak $\mathrm{CO}_{2}$ band response to aerosol height and $\mathrm{CO}_{2}$ concentration changes resemble each other, meaning that they cannot be independently retrieved if only this band was used. These interference errors get more complex once all bands and Jacobians are considered simultaneously. However, this interference can be readily investigated using information content analysis, as described in the following section.

\subsection{Information content analysis framework}

The formal characterisation of the information content and retrieval error does not require an actual retrieval step, but can be evaluated at the linearisation point (the a priori in our case) under the assumption that the forward model is linear within the range of measurement noise. In our case, two matrices characterising the retrieval are of particular interest. The averaging kernel matrix $\mathbf{A}$ links changes in the retrieved state vector $\hat{\boldsymbol{x}}$ to changes in the true state vector $\boldsymbol{x}$ (Rodgers, 2000).

$$
\frac{\partial \hat{\boldsymbol{x}}}{\partial \boldsymbol{x}}=\mathbf{A}=\mathbf{G K}
$$

where $\mathbf{G}$, the retrieval Gain matrix reads 

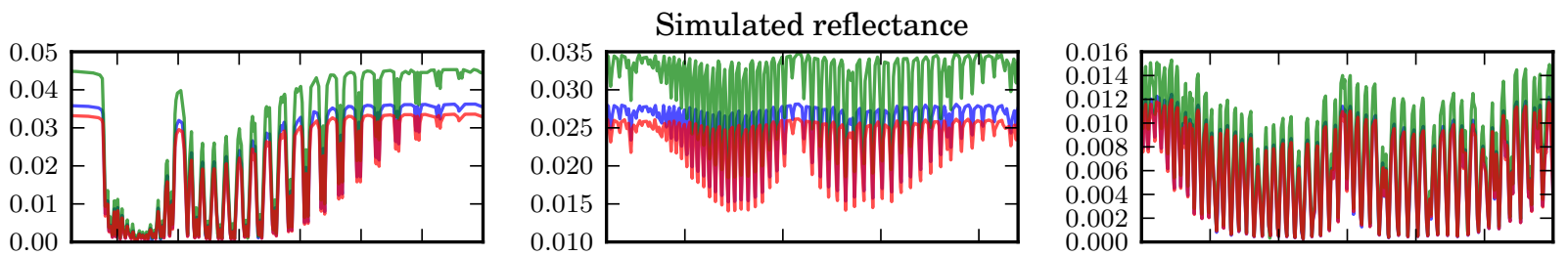

Below: Jacobians of reflectance with respect to
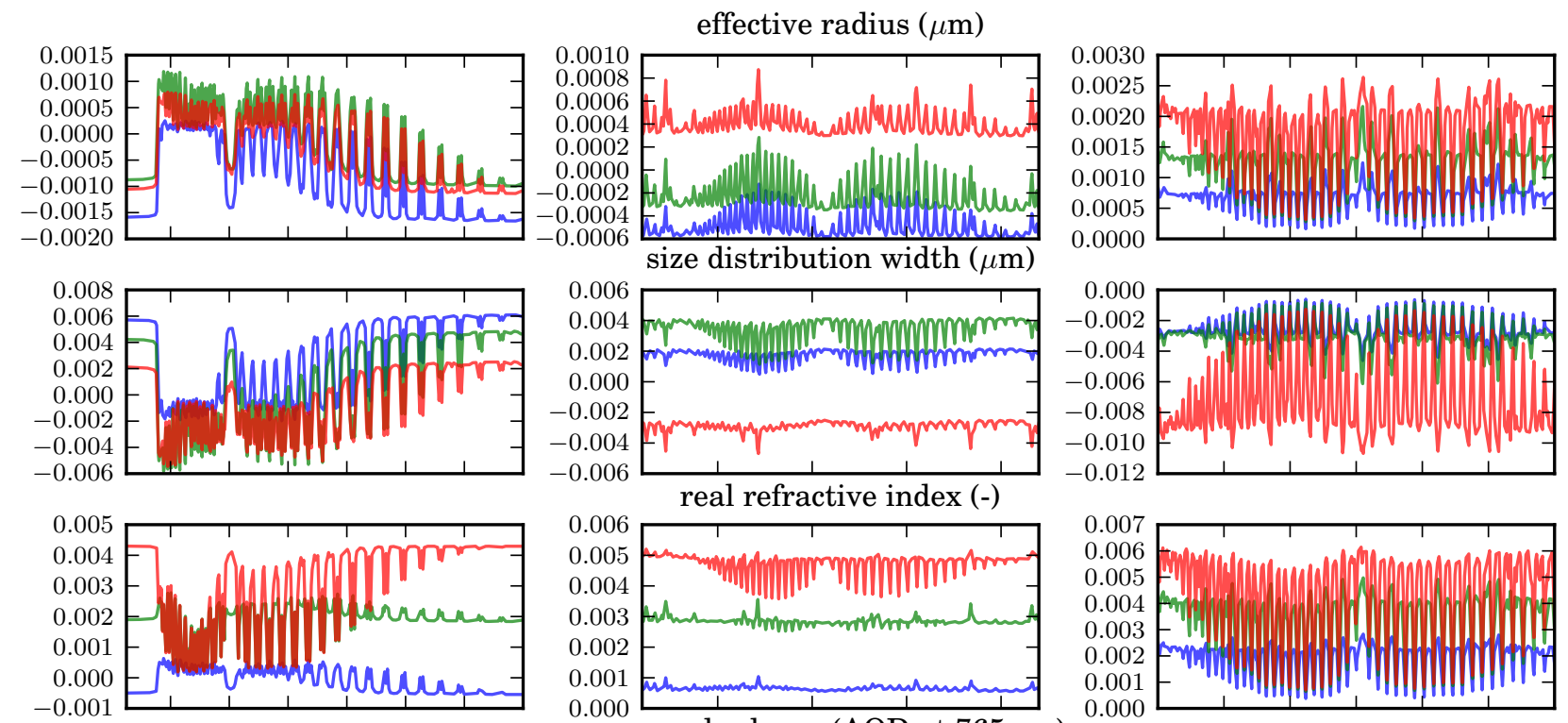

aerosol column (AOD at $765 \mathrm{~nm}$ )
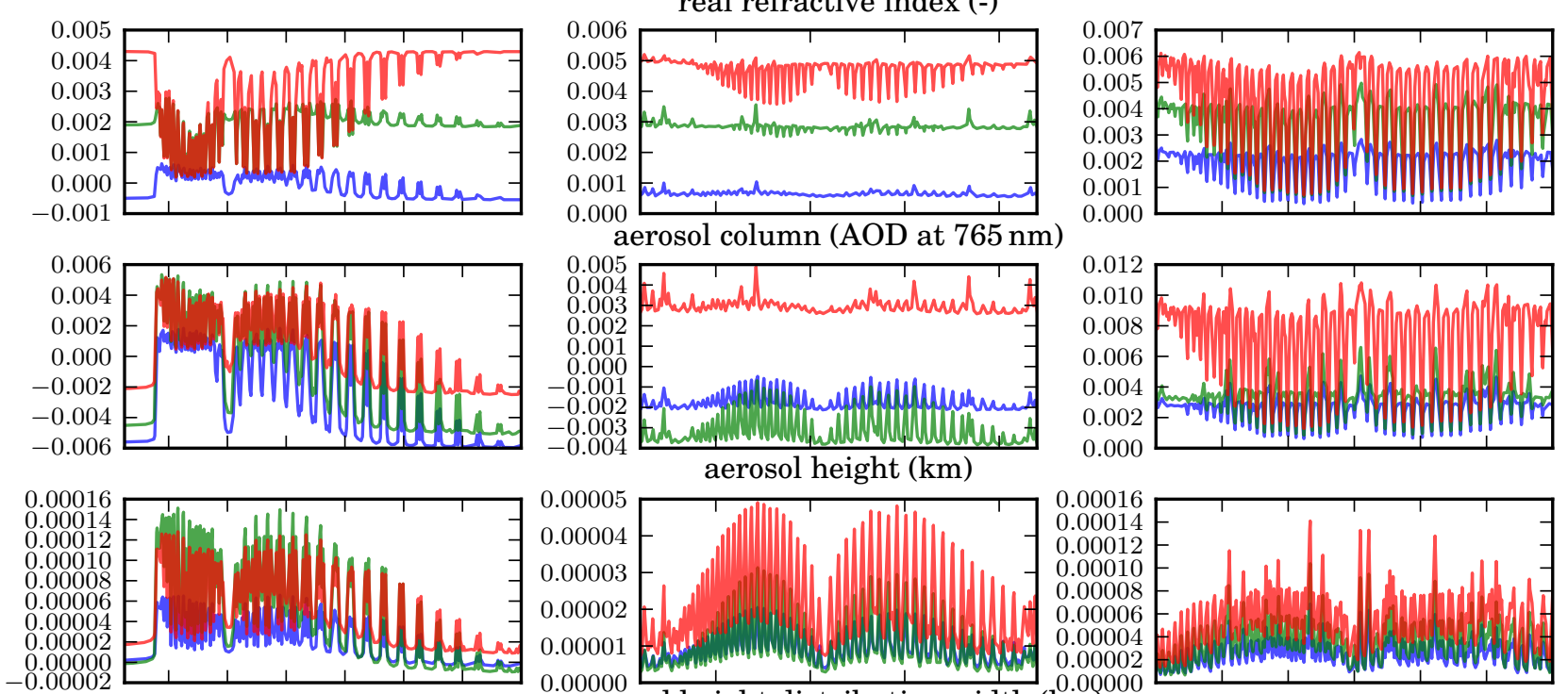

$-0.00002$

aerosol height distribution width $(\mathrm{km})$
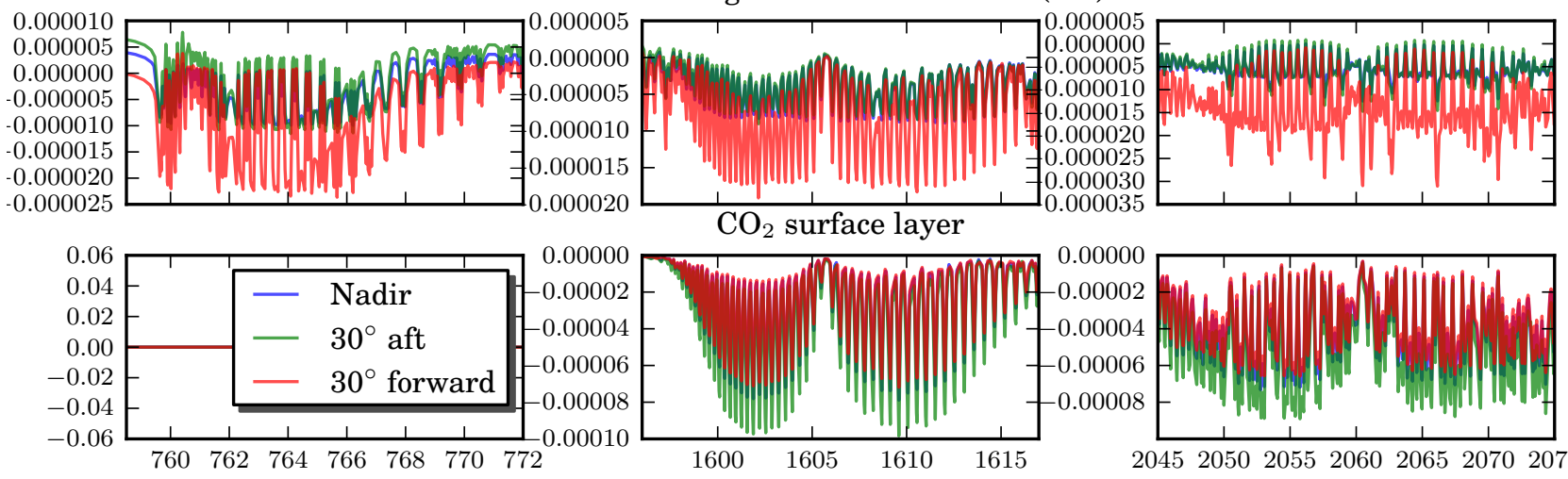

$$
\mathrm{CO}_{2} \text { surface layer }
$$

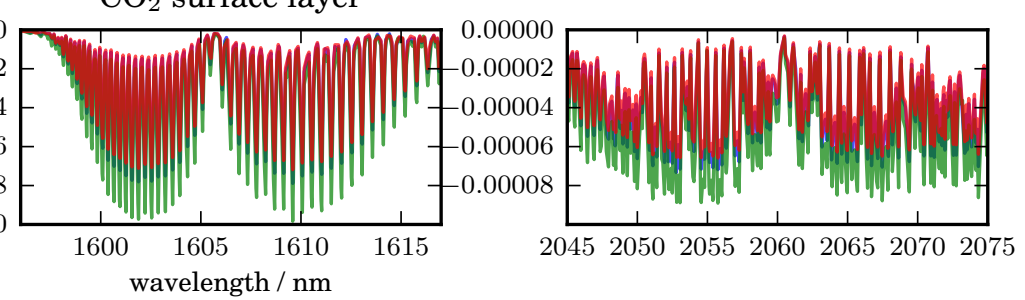

Fig. 2. Top panels: simulated spectral radiances at top-of-atmosphere for the $\mathrm{O}_{2} \mathrm{~A}$-band (left, $0.04 \mathrm{~nm} \mathrm{FWHM),} \mathrm{the} \mathrm{weak} \mathrm{CO}_{2}$ band (centre, $0.075 \mathrm{~nm} \mathrm{FWHM}$ ) and the strong $\mathrm{CO}_{2}$ band (right, $0.1 \mathrm{~nm} \mathrm{FWHM)}$ in the large SZA $\left(65^{\circ}\right)$ case. Rows below: spectral Jacobians with respect to various aerosol microphysical, amount and vertical distribution properties. Bottom panels: Jacobian with respect to a change in $\mathrm{CO}_{2}$ concentration near the surface. 

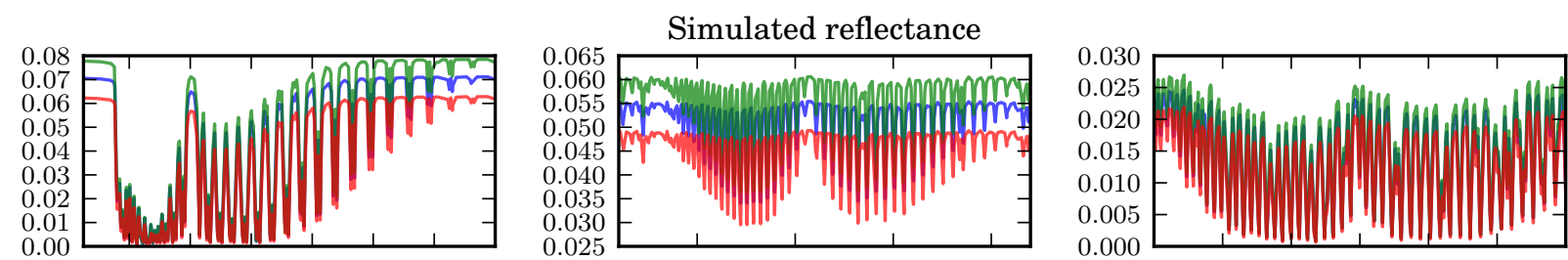

Below: Jacobians of reflectance with respect to

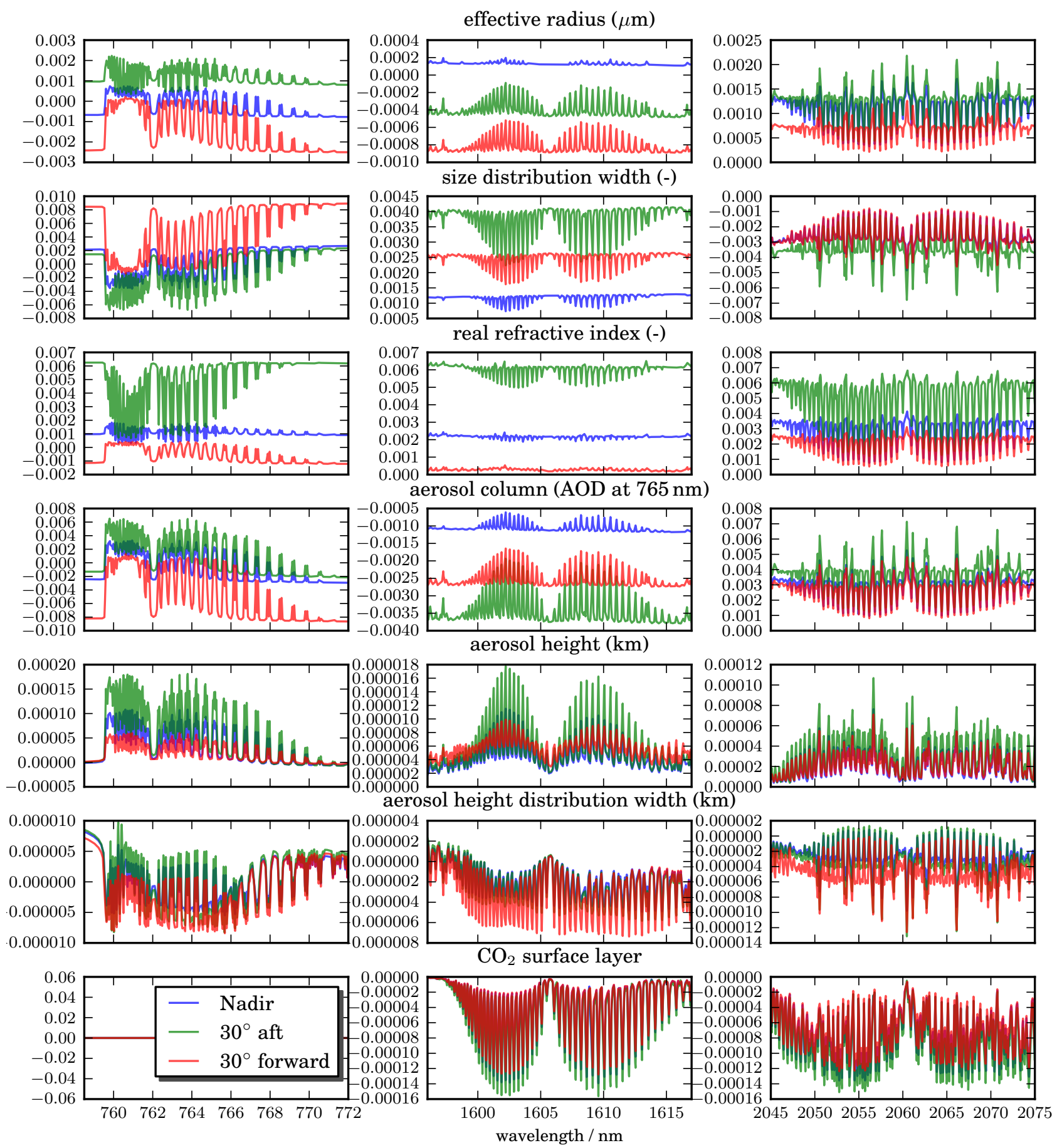

Fig. 3. Top panels: simulated spectral radiances at top-of-atmosphere for the $\mathrm{O}_{2}$ A-band (left, $0.04 \mathrm{~nm} \mathrm{FWHM),} \mathrm{the} \mathrm{weak} \mathrm{CO}_{2}$ band (centre, $0.075 \mathrm{~nm}$ FWHM) and the strong $\mathrm{CO}_{2}$ band (right, $0.1 \mathrm{~nm}$ FWHM) in the small SZA $\left(20^{\circ}\right)$ case. Rows below: spectral Jacobians with respect to various aerosol microphysical, amount and vertical distribution properties. Bottom panels: Jacobian with respect to a change in $\mathrm{CO}_{2}$ concentration near the surface. 


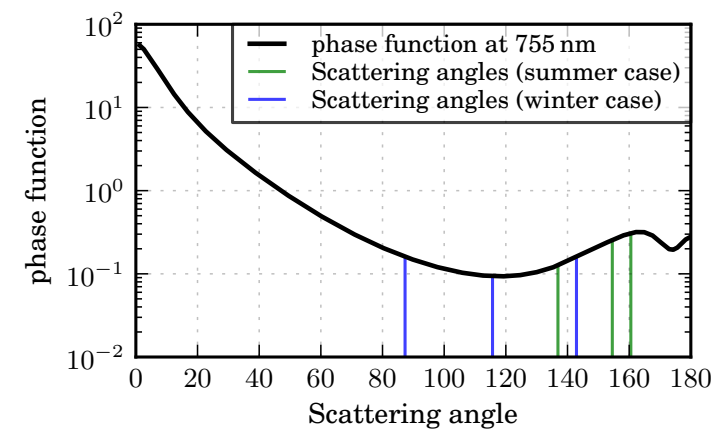

Fig. 4. Phase function of the aerosol type used in this study. Scattering angles for the summer and winter case are indicated by green and blue lines, respectively.

$\mathbf{G}=\left(\mathbf{K}^{T} \mathbf{S}_{\epsilon}^{-1} \mathbf{K}+\mathbf{S}_{\mathrm{a}}^{-1}\right)^{-1} \mathbf{K}^{T} \mathbf{S}_{\epsilon}^{-1}$.

In other words, the averaging kernel matrix quantifies the ability of the retrieval to infer deviations of state vector elements from the linearisation point. If $\mathbf{A}$ was an identity matrix, it would represent a perfect retrieval, reproducing changes for all state vector elements without any interferences. The trace of $\mathbf{A}$ represents the degrees of freedom (DOF), i.e., the amount of independent pieces of information a retrieval provides.

The a posteriori error covariance matrix $\hat{\mathbf{S}}$ describes the statistical uncertainties in retrieved $\hat{\boldsymbol{x}}$ due to measurement noise and smoothing:

$\hat{\mathbf{S}}=\left(\mathbf{K}^{T} \mathbf{S}_{\epsilon}^{-1} \mathbf{K}+\mathbf{S}_{\mathrm{a}}^{-1}\right)^{-1}$.

Table 1 lists all state vector elements used in the retrieval and their respective a priori and a priori covariance, necessary to derive the quantities described above.

For the measurement error covariance matrix $\mathbf{S}_{\epsilon}$, we define the signal-to-noise ratio SNR as the ratio at the continuum level, i.e., outside of the absorption bands. We assume a grating spectrometer, for which the noise level within the absorption lines scales with $\sqrt{\text { signal }}$ and we assume a noise floor (at zero signal) of $0.02 \%$ of the absolute continuum level radiance level.

\section{Information content for individual aerosol parameters}

In this section, we analyse the information content with respect to aerosol state vector elements only. In the standard setup, we use OCO-2 like spectral resolution (FWHM $=0.04 \mathrm{~nm}, 0.075 \mathrm{~nm}$ and $0.1 \mathrm{~nm}$ in the $\mathrm{O}_{2}$ A-band, weak $\mathrm{CO}_{2} / \mathrm{CH}_{4}$ band and strong $\mathrm{CO}_{2}$ band, respectively; 2.5 spectral samples per FWHM). The inclusion of the strong $\mathrm{CO}_{2}$ band in OCO-2 and GOSAT was motivated by the ability to derive more aerosol properties, especially the wavelength dependence of scattering properties (determined to a large extent by the size distribution). Since SCIAMACHY (Bovensmann et al., 1999) and potentially future missions provide spectra in the $\mathrm{O}_{2} \mathrm{~A}$-band and weak $\mathrm{CO}_{2} / \mathrm{CH}_{4}$ band only, we also consider a case where the strong $\mathrm{CO}_{2}$ band is dropped. In the following, these two cases are referred to as 3-band and 2-band retrieval.

\subsection{The standard 3-band and 2-band retrieval}

The ability to retrieve microphysical aerosol properties can be largely explained by the averaging kernel. Figures 5-6 show the diagonal elements of the averaging kernel for all aerosol state vector elements using the two different observation scenarios (Lamont summer and winter case). For this case, we use an $\mathrm{SNR}=200$ for all bands and viewing angles (i.e., comparable to a $\sqrt{3} \cdot 200 \approx 350$ SNR for a nadir-only sounder).

Considering the 3-band case, the multi-angle retrieval provides significant additional information, but for the aerosol height, for which all other setups already achieve averaging kernels close to 1 . The additional information in multi-angle mode is most striking for the real and imaginary part of the refractive index. The improvement is also more striking for the large solar zenith angle case (Fig. 6), mostly because a larger range of scattering angles is sampled (see Table 2). In general, especially aerosol parameters which alter the phase function (see Fig. 4) will be retrieved with higher accuracy as the potentially dominant single-scattering contribution is sampled at various angles. The added value, however, depends on the range of sampled scattering angles. The discrepancy between nadir and multi-angle mode is larger at the larger solar zenith angle, where the ability to retrieve aerosols drops in the nadir mode while it increases in the multi-angle mode (compare, e.g., the size distribution width). In fact, all averaging kernels are close to unity for the 3-band multiangle case at the large solar zenith angle. This underlines the potential to independently retrieve 7 aerosol parameters including two parameters for the height distribution, which are crucial parameters for the radiative impact of aerosols, but not retrievable without the use of absorption bands.

Comparing the 2-band and the 3-band mode, we now formally quantify what has always been implicitly assumed: The strong $\mathrm{CO}_{2}$ band in the nadir-mode contributes substantially to the aerosol retrieval. However, the 2-band multiangle retrieval setup outperforms the 3-band nadir retrieval, showing that a loss of the strong $\mathrm{CO}_{2}$ band could be more than compensated by recording multiple viewing geometries.

\subsection{Degree of freedom (DOF) analysis for aerosol parameters using diverse spectrometer specifications}

In this section, we investigate how the degrees of freedom for the aerosol state vector elements depend on the spectral resolution (FWHM) as well as SNR of the respective parameters. 


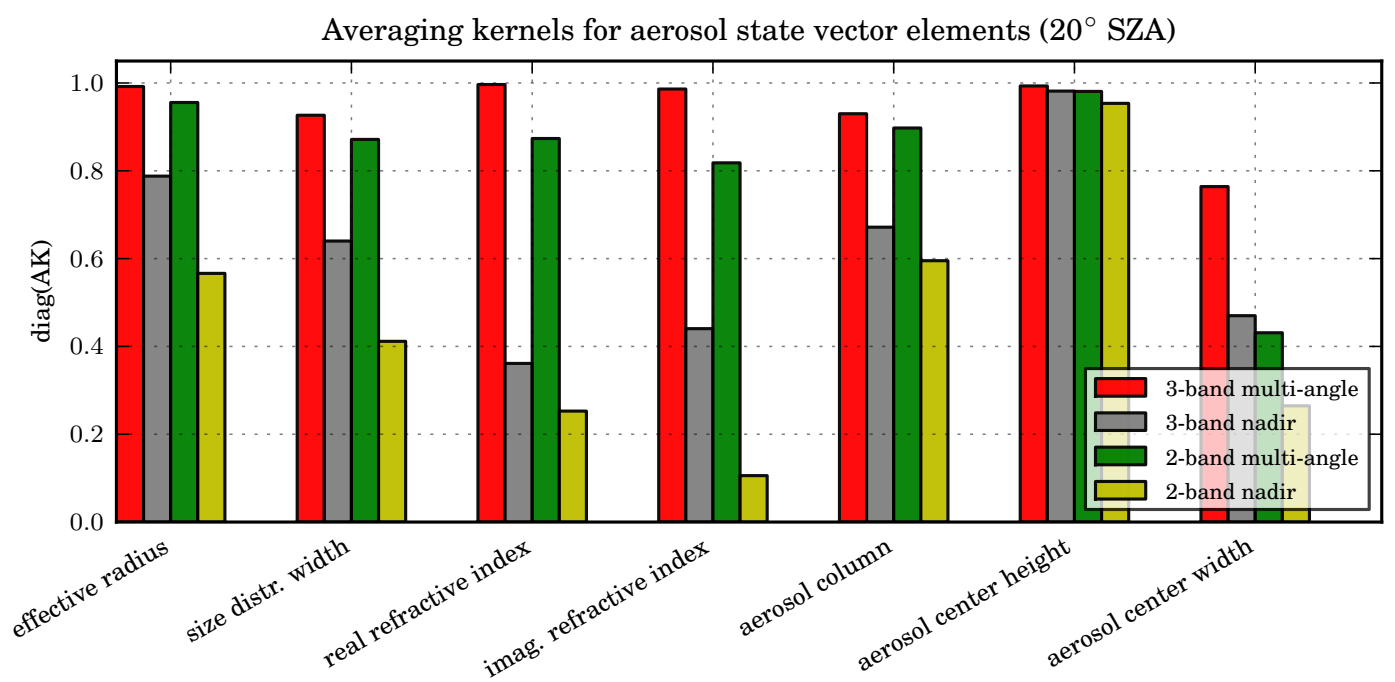

Fig. 5. Averaging kernel diagonal elements related to aerosols in the small solar zenith angle case $\left(\approx 20^{\circ}\right)$. FWHM $=0.04 \mathrm{~nm}, 0.075 \mathrm{~nm}$ and $0.1 \mathrm{~nm}$ in the $\mathrm{O}_{2}$ A-band, weak $\mathrm{CO}_{2} / \mathrm{CH}_{4}$ band and strong $\mathrm{CO}_{2}$ band, respectively; 2.5 spectral samples per FWHM, SNR =200 for each band.

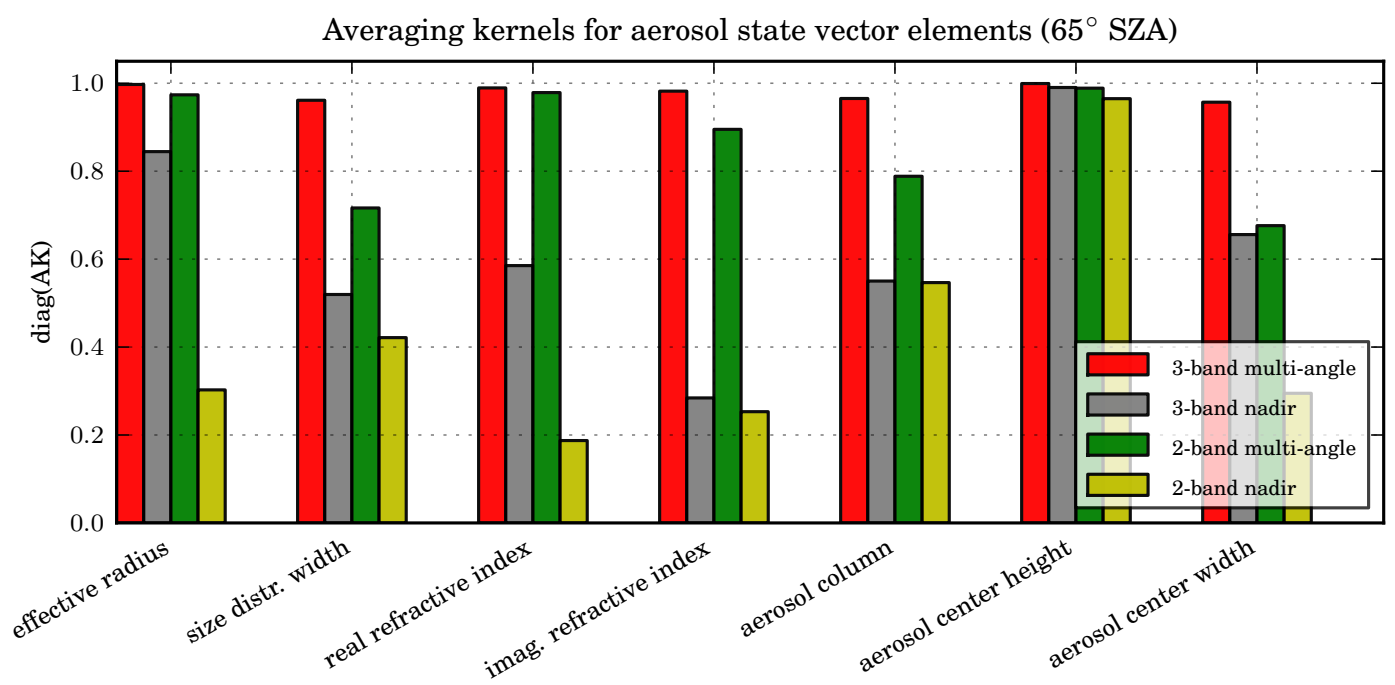

Fig. 6. Averaging kernel diagonal elements related to aerosols in the large solar zenith angle case $\left(\approx 65^{\circ}\right)$. Otherwise, same as Fig. 5 .

For this purpose, we iterate through SNR and FWHM for each individual band while keeping the other 2 bands at the nominal specifications. Important to note is that we keep the spectral sampling interval constant at the highest spectral resolution considered. Otherwise, we would confuse a loss of information at increasing FWHM due to less detector pixels with a loss of information due to the decreasing ability to sample the individual absorption line-shapes. At large FWHM, the spectra are, thus, heavily oversampled.

Figure 7 shows the contour plots of the aerosol DOFs as a function of SNR and FWHM in the small solar zenith angle case. DOF is determined by the trace of $\mathbf{A}$ considering aerosol elements only (i.e., the sum of the diagonal elements depicted in Figs. 5-6). The top row shows the multi-angle mode and the lower row the nadir-only mode. The change of DOF for a vanishing SNR is equivalent to a change caused by a loss of the respective channel. This is, non-surprisingly, most striking for the $\mathrm{O}_{2}$ A-band, where contour lines at low SNR become very dense and indiscernible, indicating a rapid loss of DOF. To some degree, this is also seen in the strong $\mathrm{CO}_{2}$ band, but not at all in the weak $\mathrm{CO}_{2}$ band. This is formally confirming another assumption often made for greenhouse-gas retrievals, viz. that the weak band hardly adds aerosol information.

Somewhat surprising is the behaviour of DOF with FWHM, especially for the $\mathrm{O}_{2}$ A-band as well as the strong $\mathrm{CO}_{2}$ band. Especially at lower SNRs, a degradation of spectral resolution hardly affects the ability to retrieve aerosols. 



Fig. 7. Small solar zenith angle case $\left(\approx 20^{\circ}\right)$ : contour plot visualisation of the degrees of freedom $(\mathrm{DOF})$ for aerosol state vector elements as a function of signal-to-noise ratio (SNR) and spectral resolution (in full width at half maximum (FWHM) of the instrument line-shape ILS). Note that oversampling of the ILS increases with FWHM in order to keep the amount of detector pixels used in the retrieval constant. In each panel, specifications of only one spectrometer (left panel: $\mathrm{O}_{2} \mathrm{~A}$-band, middle panel: weak $\mathrm{CO}_{2}$ band, right panel: strong $\mathrm{CO}_{2}$ band) were changed while the remaining two were kept at nominal levels: FWHM $=[0.04 \mathrm{~nm} ; 0.075 \mathrm{~nm} ; 0.1 \mathrm{~nm}], \mathrm{SNR}=[150 ; 150 ; 150]$ for the $\mathrm{O}_{2}$ A-band, weak $\mathrm{CO}_{2}$ band and strong $\mathrm{CO}_{2}$ band, respectively. The top row shows the multi-angle case, the bottom row the pure Nadir viewing case. Black lines indicate a 0.25 unit change in DOF.

In our case, we fit the entire band and the plot suggests that the broad-band continuum variations caused by the far linewings of strong $\mathrm{O}_{2}$ and $\mathrm{CO}_{2}$ lines contribute substantially to DOF and that the ability to actually fully sample individual absorption lines is not necessarily required. For the strong $\mathrm{CO}_{2}$ band, the spectral resolution appears to be somewhat more important than for the $\mathrm{O}_{2}$ A-band (larger gradients in the FWHM axis). It also appears that the added value of high spectral resolution can only be fully exploited at high SNR (iso-lines are more curved instead of vertical at high SNR), underlining that fully resolved lines also have to be sampled at high SNR in order to be useful. An important caveat is that higher spectral resolution facilitates the detection of systematic residuals (e.g., due to interfering species and/or lineshape misrepresentation), potentially hidden in lower resolution spectra. However, these general tradeoffs could play a role in the design of future instruments where moderate spectral resolutions could be more cost-effective.

Considering the large solar zenith angle case (Fig. 8), the DOF for the multi-angle mode saturates to its maximum value of 7 (as only 7 state vector elements were considered). A more complex aerosol setup (e.g., bi-modal and/or inclusion of cirrus clouds) would enable us to quantify the full potential of the multi-angle mode. As this is a conceptual study outlining the benefits of multiple viewing modes for potential future measurements in general and the OCO- 2 target mode in particular, this is beyond the scope of the current study.

\section{Impact on greenhouse gas posterior errors}

So far, we have only focused on the ability to retrieve aerosol properties, but not on the impact of this capability on the greenhouse gas retrieval itself, which is the primary focus of the missions under consideration in this study. For this purpose, we evaluate the posterior error covariances of the standard cases described in Sect. 3.1. Interference errors in a statistical sense are implicitly included in $\hat{\mathbf{S}}$, esp. as we ascribe large a priori uncertainties for the aerosol parameters. This could potentially lead to instabilities in the real retrieval; thus, they would be more constrained if we were to actually perform a full fit (such as in the simplified parameterisation in Butz et al. (2009), where the amount of fitted aerosol parameters is reduced while maintaining the ability to fit the spectra within the noise). For the purpose of the quantification of the impact of aerosols on errors in greenhouse-gas 

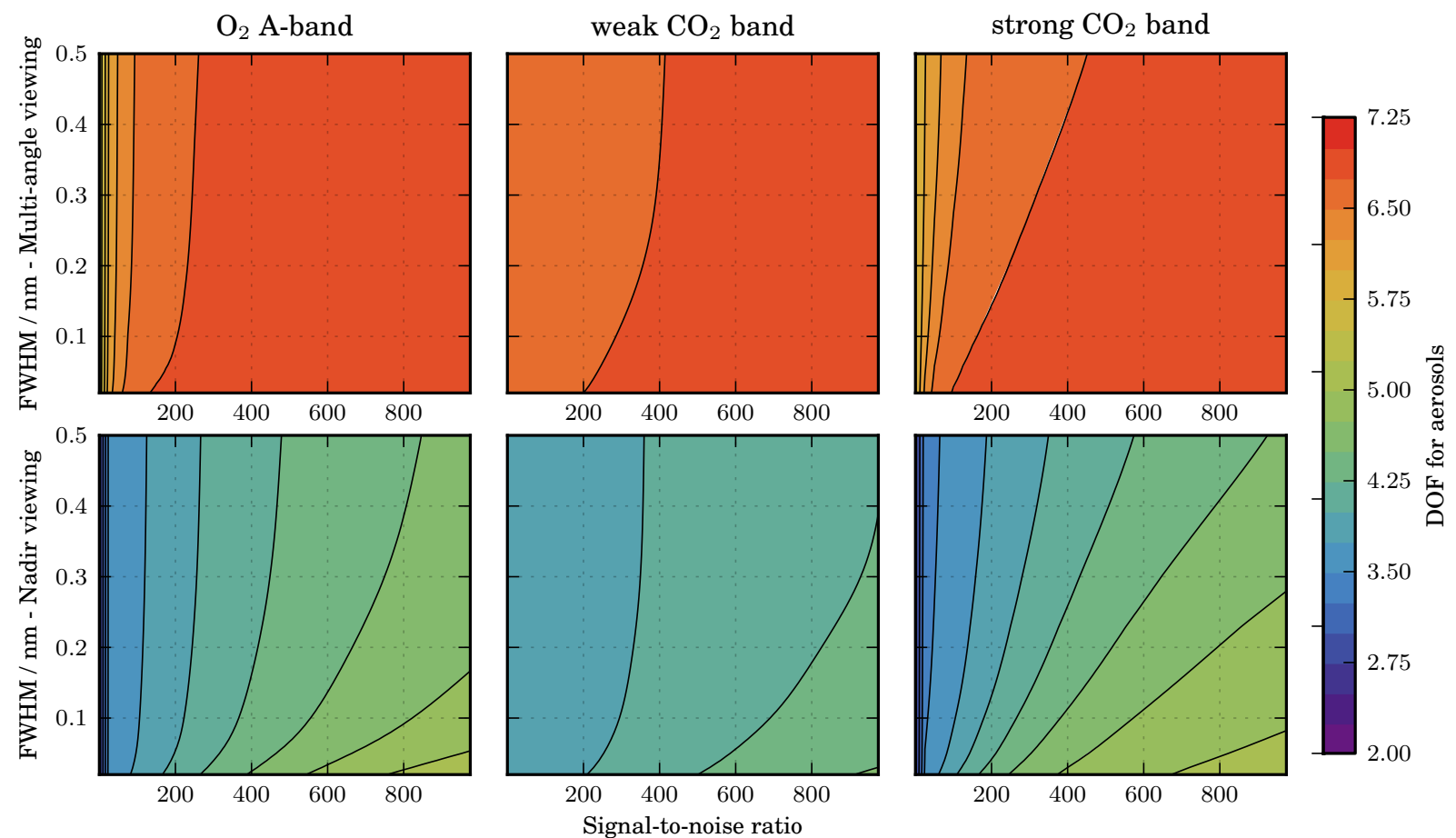

Fig. 8. Large solar zenith angle case $\left(\approx 65^{\circ}\right)$. Otherwise like Fig. 7. Note that the theoretically maximum of DOF in our setup is 7 , i.e., the total amount of aerosol state vector elements.

retrievals, our setup with larger prior uncertainties reflects reality more closely. The true interference error will be even larger as we only considered a mono-modal size distribution and did not account for potential thin cirrus clouds or multiple aerosol layers.

Figures 9-10 show the square-root of the diagonal of the posterior covariance matrix of the retrieved total greenhouse gas column amounts (for $\mathrm{CO}_{2}$, the variance in the total column was calculated as $h^{T} \hat{\mathbf{S}} h$, where $h=1$ for $\mathrm{CO}_{2}$ subcolumn indices and 0 elsewhere). As in Sect. 3.1 we consider a 3-band, 2-band as well as multi-angle and nadir-only retrieval. The respective errors as \% of the background total column are shown for $\mathrm{O}_{2}, \mathrm{CO}_{2}$ and $\mathrm{CH}_{4}$, respectively. For the sake of completeness covering all major greenhouse gases, we added a methane fit window in band 2, allowing us to determine this uncertainty in addition. The wide coloured bars indicate the posterior error of our full retrieval while the hashed area indicates the error in the absence of aerosol interference (equivalent to a perfect a priori knowledge of aerosols). To quantify this purely measurement noise related error, we zero'ed out Jacobian elements related to aerosols and BRDF kernels and subsequently computed a modified $\hat{\mathbf{S}}$. The figures convey several crucial aspects: (I) in multi-angle mode, the retrieval error is very close to the theoretical limit without aerosol interference, (II) the 2-band nadir-only retrievals clearly show the largest error contribution from the uncertainly in aerosol parameters, (III) $\mathrm{CH}_{4}$ 2-band, but multi-angle retrievals outperform 3-band nadironly retrievals.

It is important to note that the quantification of the aerosolrelated error in greenhouse gas retrievals is an underestimate of what will happen in reality as we only considered 7 aerosol state vector elements. The improvement in the posterior error should also be evaluated in terms of discrepancy to the theoretical minimum precision error (interference-free, hashed), not in absolute terms only. In addition, aerosol related errors, unlike the purely noise related errors indicated by the hashed bars, will not be statistical in nature unless the true aerosol scenarios would indeed be properly described by our a priori value and a priori covariance choice. Thus, the standard error in aggregated averages of $N$ samples will not be reduced by a factor $\sqrt{N}$, but remain constant and exhibit spatial variability. Since the amount of samples from space can be increasingly large, standard errors based on purely statistical noise can become entirely misleading, resulting in a substantial underestimation of the true error. However, the results presented here show that we can dramatically reduce the systematic interferences using a multi-angle technique, ensuring that the largest error contribution is random. Instead of flying multiple greenhouse gas satellites in nadir-only mode, it would, thus, be more worthwhile to think about different viewing strategies, which directly tackle the fundamental source of error, i.e., aerosols. 


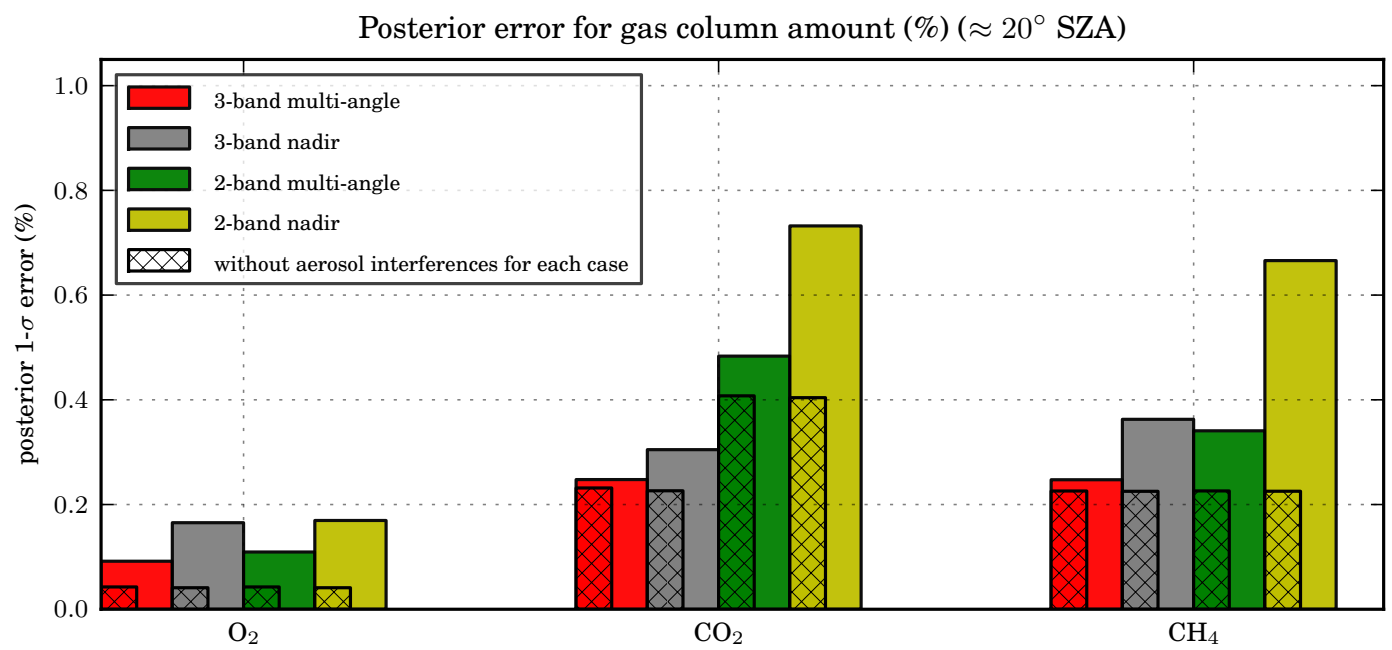

Fig. 9. Posterior error estimates $(1 \sigma)$ of trace gas total column amount in \%. Summer case (see Table 2), OCO-2 spectral resolutions and $\mathrm{SNR}=200$ for each spectrum was assumed.

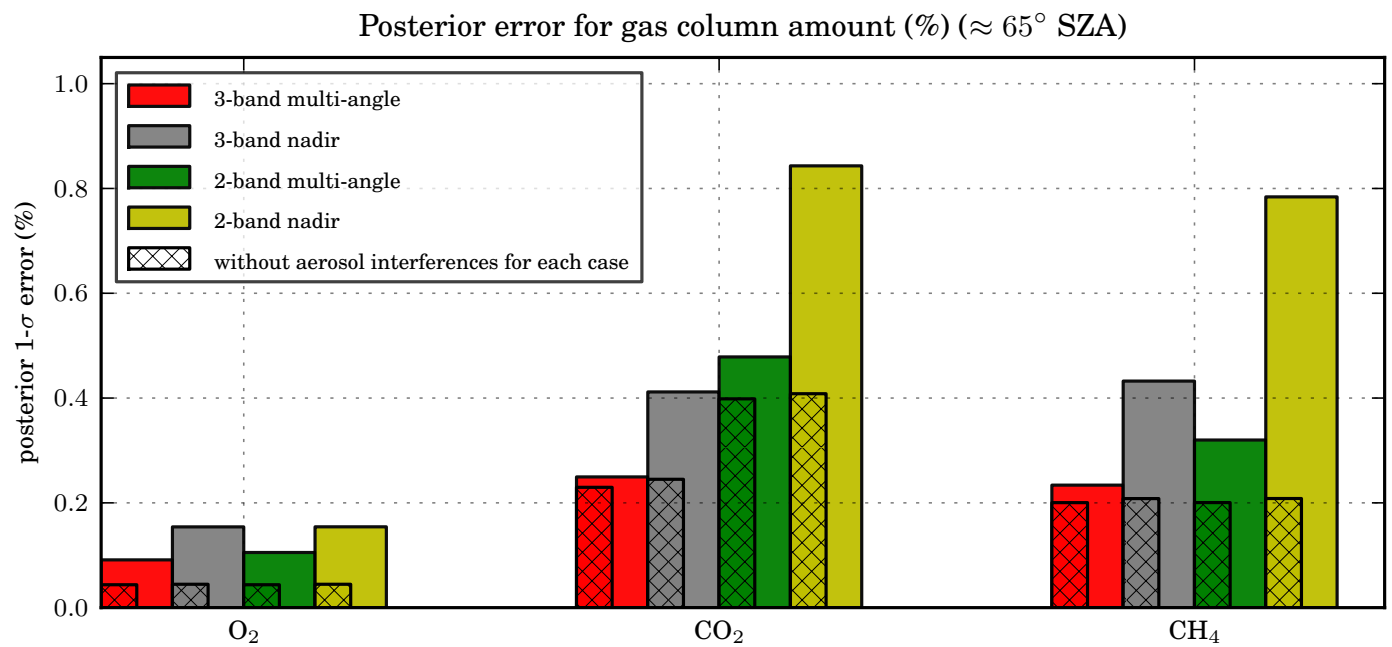

Fig. 10. Posterior error estimates $(1 \sigma)$ of trace gas total column amount in $\%$. Winter case (see Table 2), OCO-2 spectral resolutions and $\mathrm{SNR}=200$ for each spectrum was assumed.

\section{Outlook}

This study quantifies the potential of multi-angle highspectral resolution retrievals to both improve aerosol retrievals and reduce interference errors in trace gas retrievals. We have currently not yet implemented a full iterative retrieval, but evaluated the information content around the linearisation point. In the future, the full iterative multi-angle retrieval technique will have to be tested against simulated radiances such as in Butz et al. (2009) and O'Dell et al. (2012) in order to evaluate the impact of forward model errors using a wider variety of aerosol types and distributions, viewing angles as well as surface albedos. The impact of various viewing angles will also have to be evaluated. Larger viewing angles should in principle carry more independent information (increased variety of airmass and scattering angles), but would demand higher fidelity in spectroscopic parameters as airmass increases (because line-wing effects get more important if absorption lines saturate in the core). Further, ground-pixel sizes as well the area of the atmospheric light-path distribution projected on the ground largely increases, potentially violating the assumption of horizontal homogeneity used in this study. However, if entire areas are imaged with this technique using multiple footprints, tomographic methods could be envisioned. We find $30^{\circ}$ to be a good compromise as both airmass and footprint size increase only marginally $(\approx 15 \%)$, yet already substantially improving the information content.

Given the higher fidelity of the multi-angle retrieval, the OCO-2 target mode could in principle also be used to 
validate nadir-only retrievals in regions devoid of TCCON ground-based validation sites. While this internal retrieval validation is certainly not the ideal validation strategy, it may be the only viable one in regions where ground-based validation is not possible and observed $\mathrm{CO}_{2}$ variability controversial (e.g., showing large model-measurement mismatches with ambiguity as to whether it is a true signal or a measurement bias).

\section{Conclusions}

We have investigated the capability of multiple-viewing measurements of near-infrared intensities at high spectral resolution (covering $\mathrm{O}_{2}, \mathrm{CO}_{2}$ and $\mathrm{CH}_{4}$ absorption features) for the retrieval of aerosol properties and mitigation of interference errors with trace gas retrievals. For the simulations, we retrieve 7 parameters of a mono-modal aerosol size and height distribution as well as total column trace gas amounts of $\mathrm{CO}_{2}$ and $\mathrm{CH}_{4}$. We find that for 3 along-track viewing angles $\left( \pm 30^{\circ}\right.$, nadir) the degrees of freedom for signal (DOF) for retrieved aerosol parameters increase by $2-3$ compared to a nadir-only retrieval. The largest improvements occur for real and imaginary refractive indices. We further quantify the information content as a function of spectral resolution and signal-to-noise ratio for the $\mathrm{O}_{2} \mathrm{~A}$-band $(765 \mathrm{~nm})$, the weak $\mathrm{CO}_{2}$ band $(1600 \mathrm{~nm})$ and the strong $\mathrm{CO}_{2}$ band $(2000 \mathrm{~nm})$ and find that the $\mathrm{O}_{2}$ A-band is dominating the aerosol information, followed by the strong $\mathrm{CO}_{2}$ band and almost negligible information from the weak $\mathrm{CO}_{2}$ band. We find that at low SNR, spectral resolution of the $\mathrm{O}_{2} \mathrm{~A}$-band as well as the strong $\mathrm{CO}_{2}$ band hardly affects the aerosol DOF.

The impact of aerosol interferences on $\mathrm{CO}_{2}$ and $\mathrm{CH}_{4}$ total column amounts is quantified by comparing the posteriori error for multi-angle and nadir-only retrievals with the error in the absence of aerosols. We find that the interference error due to aerosol uncertainty is largely reduced in the multi-angle retrieval, approaching the theoretical minimum random error in the absence of aerosols. We acknowledge that, given the nonlinearity of the problem and the simplicity of our conceptual case study, the full potential regarding the reduction in interference errors induced in greenhouse gas retrievals can not yet be quantified in a general way. Towards that goal, more complex aerosol scenarios and full simulations will have to be considered for multi-angle retrievals (such as in Butz et al., 2009) in subsequent studies. However, this study conceptually shows that both aerosol and trace gas retrievals can benefit from multi-angle hyperspectral measurements covering strong absorption features. The method is directly applicable to the OCO-2 target mode and can pave the way towards future aerosol and greenhouse gas missions. Instead of multiple nadir-only greenhouse gas missions suffering from the very same systematic errors per geographic region (literally rendering enhanced sampling frequency ad absurdum), a multi-angle approach would provide an entirely independent view.

Acknowledgements. Part of the research described in this paper was carried out by the Jet Propulsion Laboratory, California Institute of Technology, under a contract with the National Aeronautics and Space Administration. All rights reserved. A. B. is supported by Deutsche Forschungsgemeinschaft (DFG) through the Emmy-Noether grant RemoteC, BU2599/1-1.

Edited by: F. Boersma

\section{References}

Bösch, H., Toon, G., Sen, B., Washenfelder, R., Wennberg, P., Buchwitz, M., de Beek, R., Burrows, J., Crisp, D., and Christi, M.: Space-based near-infrared $\mathrm{CO}_{2}$ measurements: Testing the Orbiting Carbon Observatory retrieval algorithm and validation concept using SCIAMACHY observations over Park Falls, Wisconsin, J. Geophys. Res., 111, 148-227, 2006.

Boesche, E., Stammes, P., and Bennartz, R.: Aerosol influence on polarization and intensity in near-infrared $\mathrm{O}_{2}$ and $\mathrm{CO}_{2}$ absorption bands observed from space, J. Quant. Spectrosc. Ra., 110, 223-239, doi:10.1016/j.jqsrt.2008.09.019, 2009.

Bovensmann, H., Burrows, J., Buchwitz, M., Frerick, J., Noel, S., Rozanov, V., Chance, K., and Goede, A.: SCIAMACHY: Mission objectives and measurement modes, J. Atmos. Sci., 56, 127-150, 1999.

Butz, A., Hasekamp, O. P., Frankenberg, C., and Aben, I.: Retrievals of atmospheric $\mathrm{CO}_{2}$ from simulated space-borne measurements of backscattered near-infrared sunlight: accounting for aerosol effects, Appl. Opt., 48, 3322-3336, 2009.

Crisp, D., Atlas, R. M., Breon, F.-M., Brown, L. R., Burrows, J. P., Ciais, P., Connor, B. J., Doney, S. C., Fung, I. Y., Jacob, D. J., Miller, C. E., O'Brien, D., Pawson, S., Randerson, J. T., Rayner, P., Salawitch, R. J., Sander, S. P., Sen, B., Stephens, G. L., Tans, P. P., Toon, G. C., Wennberg, P. O., Wofsy, S. C., Yung, Y. L., Kuang, Z., Chudasama, B., Sprague, G., Weiss, B., Pollock, R., Kenyon , D., and Schroll, S.: The Orbiting Carbon Observatory (OCO) mission, Adv. Space Res., 34, 700-709, 2004.

Diner, D. J., Beckert, J. C., Reilly, T. H., Bruegge, C. J., Conel, J. E., Kahn, R. A., Martonchik, J. V., Ackerman, T. P., Davies, R., Gerstl, S. A. W., Gordon, H. R., Muller, J.-P., Myneni, R. B., Sellers, P. J., Pinty, B., and Verstraete, M. M.: Multi-angle Imaging SpectroRadiometer (MISR) instrument description and experiment overview, IEEE T. Geosci. Remote, 36, 1072-1087, 1998.

Ferlay, N., Thieuleux, F., Cornet, C., Davis, A. B., Dubuisson, P., Ducos, F., Parol, F., Riédi, J., and Vanbauce, C.: Toward New Inferences about Cloud Structures from Multidirectional Measurements in the Oxygen A Band: Middleof-Cloud Pressure and Cloud Geometrical Thickness from POLDER-3/PARASOL, J. Appl. Meteorol. Clim., 49, 24922507, doi:10.1175/2010JAMC2550.1, 2010.

Hamazaki, T., Kaneko, Y., Kuze, A., and Kondo, K.: Fourier transform spectrometer for Greenhouse Gases Observing Satellite (GOSAT), in: Proceedings of SPIE, vol. 5659, p. 73, 2005. 
Hansen, J. and Travis, L.: Light scattering in planetary atmospheres, Space Sci. Rev., 16, 527-610, doi:10.1007/BF00168069, 1974.

Hasekamp, O. and Butz, A.: Efficient calculation of intensity and polarization spectra in vertically inhomogeneous scattering and absorbing atmospheres, J. Geophys. Res., 113, D20309, doi:10.1029/2008JD010379, 2008.

Hasekamp, O. and Landgraf, J.: A linearized vector radiative transfer model for atmospheric trace gas retrieval, J. Quant. Spectrosc. Ra., 75, 221-238, 2002.

Hasekamp, O. and Landgraf, J.: Linearization of vector radiative transfer with respect to aerosol properties and its use in satellite remote sensing, J. Geophys. Res., 110, D04203, doi:10.1029/2004JD005260, 2005.

Hasekamp, O. P. and Landgraf, J.: Retrieval of aerosol properties over land surfaces: capabilities of multiple-viewing-angle intensity and polarization measurements, Appl. Optics, 46, 33323344, 2007.

Herman, J., Bhartia, P., Torres, O., Hsu, C., Seftor, C., and Celarier, E.: Global distribution of UV-absorbing aerosols from Nimbus 7/TOMS data, J. Geophys. Res., 102, 16911-16922, doi:10.1029/96JD03680, 1997.

Kahn, R., Banerjee, P., and McDonald, D.: Sensitivity of multiangle imaging to natural mixtures of aerosols over ocean, J. Geophys. Res., 106, 18219-18238, 2001.

Kuze, A., Suto, H., Nakajima, M., and Hamazaki, T.: Thermal and near infrared sensor for carbon observation Fourier-transform spectrometer on the Greenhouse Gases Observing Satellite for greenhouse gases monitoring, Appl. Optics, 48, 6716-6733, 2009.

Lebsock, M., L'Ecuyer, T., and Stephens, G.: Information content of near-infrared spaceborne multiangular polarization measurements for aerosol retrievals, J. Geophys. Res., 112, D14206, doi:10.1029/2007JD008535, 2007.

Leroy, M., Deuzé, J., Bréon, F., Hautecoeur, O., Herman, M., Buriez, J., Tanré, D., Bouffiès, S., Chazette, P., and Roujean, J.: Retrieval of atmospheric properties and surface bidirectional reflectances over land from POLDER/ADEOS, J. Geophys. Res., 102, 17023-17037, doi:10.1029/96JD02662, 1997.

Litvinov, P., Hasekamp, O., and Cairns, B.: Models for surface reflection of radiance and polarized radiance: Comparison with airborne multi-angle photopolarimetric measurements and implications for modeling top-of-atmosphere measurements, Remote Sens. Environ., 115, 781-792, doi:10.1016/j.rse.2010.11.005, 2011.

Maso, M. D., Kulmala, M., Riipinen, I., Wagner, R., Hussein, T., Aalto, P., and Lehtinen, K.: Formation and growth of fresh atmospheric aerosols: eight years of aerosol size distribution data from SMEAR II, Hyytiala, Finland, Boreal Environ. Res., 10, 323-336, 2005.

Miller, C. E., Crisp, D., DeCola, P. L., Olsen, S. C., Randerson, J. T., Michalak, A. M., Alkhaled, A., Rayner, P., Jacob, D. J., Suntharalingam, P., Jones, D. B. A., Denning, A. S., Nicholls, M. E., Doney, S. C., Pawson, S., Boesch, H., Connor, B. J., Fung, I. Y., O’Brien, D., Salawitch, R. J., Sander, S. P., Sen, B., Tans, P., Toon, G. C., Wennberg, P. O., Wofsy, S. C., Yung, Y. L., and Law, R. M.: Precision requirements for space-based $\mathrm{X}-\mathrm{CO}_{2}$ data, J. Geophys. Res., 112, D10314, doi:10.1029/2006JD007659, 2007.
Mishchenko, M. I., Geogdzhayev, I. V., Cairns, B., Carlson, B. E., Chowdhary, J., Lacis, A. A., Liu, L., Rossow, W. B., and Travis, L. D.: Past, present, and future of global aerosol climatologies derived from satellite observations: A perspective, J. Quant. Spectrosc. Ra., 106, 325-347, doi:10.1016/j.jqsrt.2007.01.007, 2007.

O’Dell, C. W., Connor, B., Bösch, H., O’Brien, D., Frankenberg, C., Castano, R., Christi, M., Eldering, D., Fisher, B., Gunson, M., McDuffie, J., Miller, C. E., Natraj, V., Oyafuso, F., Polonsky, I., Smyth, M., Taylor, T., Toon, G. C., Wennberg, P. O., and Wunch, D.: The ACOS $\mathrm{CO}_{2}$ retrieval algorithm - Part 1: Description and validation against synthetic observations, Atmos. Meas. Tech., 5, 99-121, doi:10.5194/amt-5-99-2012, 2012.

Reuter, M., Buchwitz, M., Schneising, O., Heymann, J., Bovensmann, H., and Burrows, J. P.: A method for improved SCIAMACHY CO 2 retrieval in the presence of optically thin clouds, Atmos. Meas. Tech., 3, 209-232, doi:10.5194/amt-3-209-2010, 2010.

Rodgers, C. D.: Inverse Methods for Atmospheric Sounding: Theory and Practice, World Scientific, Singapore, 2000.

Roujean, J.-L., Leroy, M., and Deschamps, P.-Y.: A Bidirectional Reflectance Model of the Earth's Surface for the Correction of Remote Sensing Data, J. Geophys. Res., 97, 20455-20468, doi:10.1029/92JD01411, 1992.

Schaaf, C., Gao, F., Strahler, A., Lucht, W., Li, X., Tsang, T., Strugnell, N., Zhang, X., Jin, Y., Muller, J.-P., Lewis, P., Barnsley, M., Hobson, P., Disney, M., Roberts, G., Dunderdale, M., Doll, C., d'Entremont, R., Hu, B., Liang, S., Privette, J., and Roy, D.: First operational BRDF, albedo nadir reflectance products from MODIS, Remote Sens. Environ., 83, 135-148, doi:10.1016/S0034-4257(02)00091-3, 2002.

Wanner, W., Li, X., and Strahler, A.: On the derivation of kernels for kernel-driven models of bidirectional reflectance, J. Geophys. Res., 100, 21077-21089, doi:10.1029/95JD02371, 1995.

Wunch, D., Wennberg, P. O., Toon, G. C., Connor, B. J., Fisher, B., Osterman, G. B., Frankenberg, C., Mandrake, L., O’Dell, C., Ahonen, P., Biraud, S. C., Castano, R., Cressie, N., Crisp, D., Deutscher, N. M., Eldering, A., Fisher, M. L., Griffith, D. W. T., Gunson, M., Heikkinen, P., Keppel-Aleks, G., Kyrö, E., Lindenmaier, R., Macatangay, R., Mendonca, J., Messerschmidt, J., Miller, C. E., Morino, I., Notholt, J., Oyafuso, F. A., Rettinger, M., Robinson, J., Roehl, C. M., Salawitch, R. J., Sherlock, V., Strong, K., Sussmann, R., Tanaka, T., Thompson, D. R., Uchino, O., Warneke, T., and Wofsy, S. C.: A method for evaluating bias in global measurements of $\mathrm{CO}_{2}$ total columns from space, Atmos. Chem. Phys., 11, 12317-12337, doi:10.5194/acp11-12317-2011, 2011. 